\title{
The Colloidal Approach. A Promising Route for Asphaltene Deposition Modelling
}

\author{
L. Nabzar and M.E. Aguiléra \\ Institut français du pétrole, IFP, 1-4 avenue de Bois-Préau, 92852 Rueil-Malmaison Cedex - France \\ e-mail: lahcen.nabzar@ifp.fr - maria.aguilera@ifp.fr
}

\begin{abstract}
Résumé - L'approche colloïdale : une voie prometteuse pour la modélisation des dépôts d'asphaltènes - Il est généralement admis que les asphaltènes existent dans les bruts sous forme dissoute et particulaire et que les bruts asphalténiques se comportent en solution comme des systèmes colloïdaux. L'objectif de ce travail était de vérifier qu'en présence d'écoulement et au sein d'une matrice poreuse, les asphaltènes conservent ce comportement colloïdal. Pour cela, nous avons étudié expérimentalement la cinétique du dépôt en milieux poreux en fonction des paramètres pertinents tels que la vitesse, l'état d'agrégation des asphaltènes, le contenu en résines et l'origine de l'huile. L'étude a été menée à la fois sous des conditions bien contrôlées avec des systèmes modèles et sous des conditions plus représentatives de l'application avec des huiles réelles et des roches d'affleurement. Les résultats obtenus nous ont permis d'établir que le dépôt des asphaltènes obéit effectivement aux mêmes lois cinétiques que le dépôt des colloïdes en milieux poreux. Ils nous ont permis de proposer des lois cinétiques de type lois d'échelle de la forme $\eta \propto A \gamma^{-s}, \eta$ étant l'efficacité du dépôt et $\gamma$ le cisaillement. Les exposants, $s$, sont des exposants universels caractéristiques des régimes de dépôt alors que les préfacteurs $A$ englobent l'ensemble des autres caractéristiques spécifiques au système considéré (asphaltènes et milieux poreux). Ces lois cinétiques montrent que l'épaisseur du dépôt, qui se fait par multicouche, croît fortement lorsque le cisaillement diminue. Par conséquent, si les conditions sont favorables, la formation rapide d'un dépôt épais est attendue lors de la récupération des bruts lourds dans des formations très perméables et à des faibles vitesses d'écoulement. Un tel dépôt peut donc avoir un impact significatif sur l'efficacité de la récupération des bruts lourds. L'estimation de cet impact devrait donc faire partie intégrante de l'évaluation et de l'optimisation de tout procédé de récupération. À cette fin, l'approche dite «Colloïdale » constitue une voie nouvelle et prometteuse pour la modélisation du dépôt et de l'endommagement associé.
\end{abstract}

\footnotetext{
Abstract - The Colloidal Approach. A Promising Route for Asphaltene Deposition Modelling - It is now widely recognized that asphaltene exist in crude oils both as dissolved and particulate matter and that asphatenic crude oils behave as colloidal systems. The objective of this research work is to check if, in porous media and under dynamic conditions, asphaltene also behave as colloids. In this case, their deposition kinetic should obey the classical laws for colloid deposition in porous media. To achieve this, asphaltene deposition kinetics has been investigated as a function of the main controlling parameters such as flow rate, asphaltene aggregation state, resin content and crude origin. The study has been performed, first under well controlled condition using model fluids and porous media, and then under more representative conditions using actual crude oils and outcrop sandstones. The results confirmed that, indeed, the kinetics of asphaltene deposition in porous media obeys the general scaling low of
} 
colloid deposition. They allowed us to propose general scaling laws for the deposition kinetics in the form $\eta \propto A \gamma^{-s}, \eta$ is the capture efficiency and $\gamma$ the shear rate. The exponents $s$ are universal exponents that are characteristic of the deposition regimes while the power law pre-factors A encompass all the specific features of the system considered (asphaltene and porous media). These kinetic laws show that the thickness of the deposit increases rapidly with decreasing shear rate. Accordingly and under favourable conditions, a thick deposit is expected to form during heavy oil extraction from high permeability formations and under low flow rate conditions. Such deposition could then have significant impact on the efficiency of heavy oil recovery. Therefore, its impact on permeability and on flow properties of reservoir fluids needs to be assessed as a part of process optimisation and evaluation. The Colloidal approach provides a new and promising route for asphaltene deposition and associated permeability damage modelling.

\section{List of symbols}

A Prefactor of the deposition kinetics equation

$\mathrm{a}_{\mathrm{p}} \quad$ Particle radius

c Empirical constant of the shear rate calculation in porous media

$C_{\mathrm{o}} \quad$ Injected concentration

$C_{\text {plateau }}$ Plateau value of the Outlet concentration.

$D \quad$ Diffusion coefficient

Da Damkohler number

$d_{g} \quad$ Grain diameter

$F_{H} \quad$ Hydrodynamic force

$F_{A} \quad$ Adhesion force

$H \quad$ Hamaker constant

ID Capillary inner diameter

$J \quad$ Mean deposition flux in the presence of an energy barrier

$J_{o} \quad$ Mean deposition flux in the absence of the energy barrier

$j \quad$ Deposition flux density

$<j>\quad$ Mean deposition flux density

$L_{c} \quad$ Capillary length

$L_{\text {core }}$ Core length

$P e_{g} \quad$ Peclet number based on grain size

$P V I \quad$ Number of pore volume injected

$Q \quad$ Flow rate

$R_{c} \quad$ Capillary radius

$R_{m} \quad$ Mobility reduction

$r_{p}{ }^{o} \quad$ Mean pore throat radius

$S_{j} \quad$ Saturation of phase $j$

$S_{j \text { irr }} \quad$ Irreducible saturation of phase $j$

$s \quad$ Peclet exponent in the deposition kinetics correlation

$U_{o} \quad$ Approach velocity (Darcy)

$u \quad$ Interstitial velocity

$u_{j} \quad$ Interstitial velocity of phase $j$

$v_{j} \quad$ Superficial velocity of phase $j$
$\begin{array}{ll}V_{i n j} & \text { Volume injected } \\ V_{p} & \text { Pore volume }\end{array}$

\section{Greek}

$\beta \quad$ Collision efficiency $\left(\beta=\eta / \eta_{O}\right)$

$\delta \quad$ Distance of minimum approach

$\delta_{h} \quad$ Mean hydrodynamic thickness of asphaltene deposit

$\delta_{D} \quad$ Diffusion layer thickness

$\phi \quad$ Porosity

$\phi_{i} \quad$ Initial porosity

$\gamma \quad$ Shear rate

$\gamma_{*} \quad$ Shear rate $(*=\mathrm{c}$ : critical, $*=\mathrm{cl}$ : lower critical shear rate, $*=$ cu: upper critical shear rate)

$\eta \quad$ Capture efficiency in presence of energy barrier

$\eta_{0} \quad$ Capture efficiency in absence of energy barrier

$\eta_{\text {residual }}$ Residual capture efficiency

$\mu \quad$ Viscosity

$\theta \quad$ Azimuthal angle

$\rho \quad$ Crude density

$\rho_{d} \quad$ Deposit density

$\Sigma \quad$ Cross section of the porous medium

$\Sigma_{a}^{p} \quad$ Pore surface available for deposition

\section{INTRODUCTION}

Asphaltenes belong to a class of soluble compounds found in petroleum fluids and are functionally defined as a precipitate obtained from petroleum by adding an excess of $n$-heptane. Asphaltene constituents are the highest molecular weight and most polar constituents in crude oil. The amount and the characteristics of the asphaltene constituents depend on the origin of the crude oil. They are obtained from petroleum by separation upon the addition of non polar solvents (such as $n$ pentane, iso-pentane, $n$-heptane).

Asphaltenes are supposed to be in stable state under reservoir conditions where the pressure (reservoir pressure) is 
above the flocculation threshold. This stability, however, is easily disrupted by various destabilizing forces such as: pressure drop below the flocculation threshold, mixing with lean or rich gases (miscible floods), $\mathrm{pH}$ shifts, commingling of crude oils and adding incompatible polar solvents. Therefore, asphaltenes may undergo flocculation and separation from the oil phase due to variations in pressure, composition and temperature. Asphaltenes can be destabilized in any area of the oil production system from as far back as the near wellbore area to as far down the surface facilities and refinery. This destabilization results in flow rate restriction and productivity loss through the two min mechanisms schematised in Figure 1.

Due to their large size and their adsorption affinity at the interfaces, flocculated asphaltenes can cause irreversible deposition which may not wash away, or not easily, by current remediation techniques. Even if solvent (aromatics) squeeze can remove most of the asphaltene-induced damage, asphaltene deposition resumes again when the well is put in production. Thus, when asphaltene damage occurs within the near wellbore, remediation requires frequent treatments that participate to the increase of production costs. Deposited asphaltenes can reduce effective hydrocarbon mobility by:

- blocking the pore throats;

- adsorbing onto the rock, thereby altering both the formation wettability from water-wet to oil-wet and its absolute permeability;

- increasing hydrocarbon viscosity by nucleating and stabilizing water-in-oil emulsions.

In terms of composition, the peptizing power of the crude oil depends on its relative amounts of saturates, aromatics,

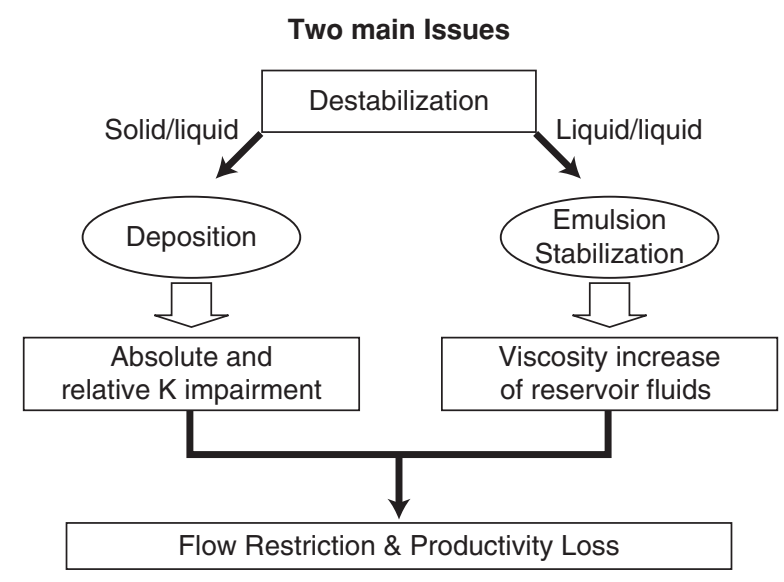

Figure 1

Asphaltene Issues in Oil Reservoirs. resins and asphaltenes. Some particular role in asphaltene stabilisation has been conferred to the resins but the actual mechanisms are still a matter of active debate. Asphaltene destabilisation is not correlated to their concentration but to the solvent quality of the remaining fraction of a crude (maltenes). Thus, in spite of their large asphaltene content, heavy oils have no tendency to drop out naturally their asphaltenes. However, heavy oil production often requires gas or solvent injection that modify the equilibrium state ( $\mathrm{pH}$ or/and composition) of asphaltene fraction increasing their tendency to aggregation and deposition. If such aggregation phenomenon could be sought for, the asphaltenic sludge left behind and the subsequent aggregate deposition on rock surface can have, at the end, detrimental impact on heavy oil extraction. Therefore, asphaltene deposition and its impact on permeability and on flow properties of reservoir fluids need to be assessed as a part of process optimisation and evaluation.

There are several models proposed for asphaltene formation damage in the literature that have attempted to model the asphaltene-induced formation damage using the following mechanisms of deposit: adsorption, deposition on surface, entrainment of deposits and pore blocking. Some of these models require many adjustable parameters, while other models are oversimplified. Wojtanowycz et al. [1] proposed a model based on filtration theory. Nghiem et al. [2] developed a compositional simulator model with an empirical linear correlation for the induced-damage factor. Civan [3] proposed a model for simultaneous deposition of paraffin and asphaltene. In this work the authors used the ideal solution theory to describe asphaltene solubility and the parallel pathway model developed by Gruesbeck and Collins [4]. Ali and Islam [5] proposed a model that incorporates asphaltene adsorption with wellbore plugging incorporating the surface excess theory and the parallel pathway model [4]. Wang et al. $[6,7]$ improved the original model of Civan to simulate simultaneous paraffin and asphaltene deposition in core tests [6] and asphaltene deposition in reservoirs [7]. Leontaritis [8]developed a model for the near-wellbore formation damage induced by blockage of pore throats by asphaltene particles using the thermodynamic colloidal model Wang et al. [9, 10] improved their model using polymer solution theory to describe the asphaltene precipitation by pressure reduction and real solution theory to describe the paraffin precipitation/dissolution. This modeling approach is used to model asphaltene deposition during primary oil recovery [9] and the simultaneous deposition of paraffin and asphaltene [10]. Regarding asphaltene deposition three main mechanisms have been considered: surface deposition, pore throat plugging and erosion effect (reentrainment). The local permeability reduction $\left(k / k_{0}\right)$ is calculated from the local porosity reduction $\left(\phi / \phi_{0}\right)$ using a cubic relationship with a pore connectivity parameter. These models are used to build a three dimensional and three phase black oil simulator. More 
recently, Civan [11] addressed in detail reservoir formation damage, including modeling, assessment and mitigation. A comprehensive description of organic deposition and associated formation damage can be found in [11].

Nabzar et al. [12-15] proposed a new approach for asphaltene deposition modeling that is called the "Colloidal Approach" and based on the theory of colloid transport and deposition in porous media and taking into account the specific feature of asphaltene particles such us their loose structure and their tendency to form multilayer deposition. This colloidal approach has been used successfully to model the deposition kinetics of different kind of colloid such as solid particles [16] and emulsion droplets [17]. This approach has been recently $[15,18]$ experimentally validated through a systematic and thorough experimental investigation of the asphaltene deposition kinetics using different systems and under different experimental conditions. These include both model system that consisted in Safania asphaltene dissolved in toluene and capillaries and more representative system that consisted in Weyburn crude oil and Fontainebleau sandstones.

The aims of the this paper are first, to give a briefly synthesis of our previous work dedicated to the "Colloidal approach" validation, then to present and discuss some new validation results supporting our modelling approach and obtained using crude oils from different origins.

\section{THE COLLOIDAL APPROACH}

The deposition of particles on any collector from a dispersion fluid occurs in two successive steps (Fig. 2):

- The transport from the bulk to the vicinity of the collector which is governed by convection (forces exerted by the viscous fluid on the particle) and diffusion (Brownian forces), and

- The attachment to the collector surface which is determined by diffusion, particle/pore surface interactions and hydrodynamic interactions with a possible contribution of hydrodynamic forces. The nature and extent of this contribution depend on both the location inside porous structure and deposition regime.

For particles much smaller than the permeability-determining pore throats, only surface deposition can occur without any pore restriction blockage. In this case, successive deposition regimes can be defined as the convection-to-diffusion forces ratio increases. This ratio is referred to as the grain Peclet number and defined as:

$$
P e_{g}=\frac{2 \cdot U_{o} \cdot d_{g}}{D}
$$

where $U$ is the approach velocity, $D$ the particle diffusion coefficient, and $d_{g}$ is the grain diameter.
According to the convection-to-diffusion force ratio, Chauveteau et al. [16] defined the following deposition regimes:

- pure diffusion deposition regime,

- the convective-diffusion deposition regime,

- hydrodynamic deposition regime,

- interception regime.

The initial capture efficiency, $\eta_{o}$, is defined as the ration of deposition flux to incident flux:

$$
\eta_{o}=\frac{\text { Mean } \cdot \text { deposition flux }}{\text { incident flux }}=\frac{J_{0}}{Q C_{0}}
$$

If particles are already deposited onto the collector surface, particle/particle interactions will play an important role in the deposition kinetics. They can lower the deposition rate for highly stable and repulsive particles (blocking effect) or act as new collectors and enhance the capture efficiency for weakly repulsive or attractive particles (multilayer deposition).

For stable colloidal particles, the deposition kinetics has been theoretically investigated by several authors under different regimes and using different approximations. In the convective-diffusion deposition regime $\left(P e_{g}>>1\right)$ and in the framework of the Smoluchowski-Levich Approximation (SLA) where Van der Waals attractions are counterbalanced by hydrodynamics interactions, the capture efficiency takes the form:

$$
\eta_{o}=A \cdot P e_{g}^{-2 / 3}
$$

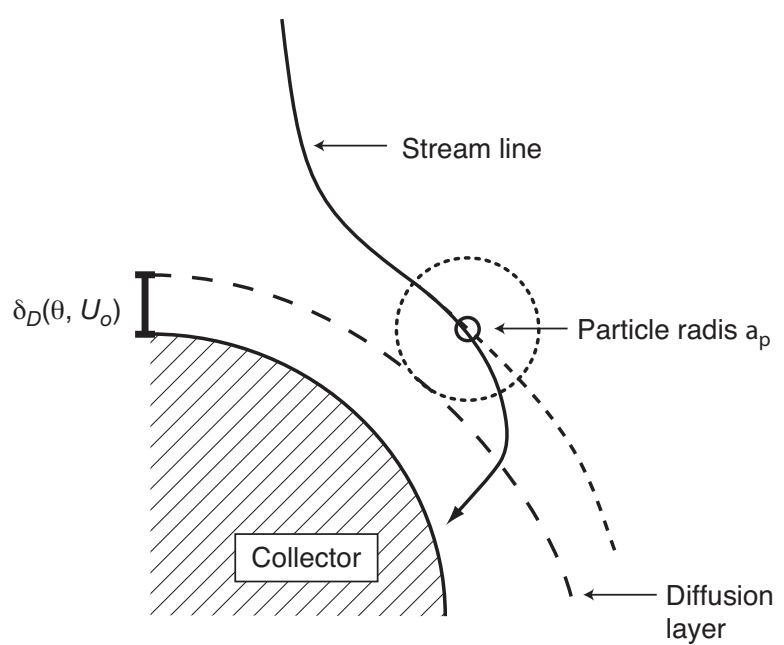

$\delta_{D}\left(\theta, U_{o}\right)$ : Diffusion layer thicness, which increases as $\theta$ increases and diminishes as the flow rate increses

Figure 2

Schematic view of particle transport to collector surface. 
$A$ depends on the flow field around the collector and on collector geometry, being equals to 4 for an isolated spherical collector [19], 12 for a random pack of spheres [20] and 24 for a random pack of well-sorted sharp-edged grains [21].

When an energy barrier facing particle deposition on the collector surface exists, the initial capture efficiency $\eta$ may be approximated by (Interaction Force Boundary Layer Approximation: IFBLA) $[22,16]$ :

$$
\eta=\beta \eta_{0}=\frac{D a}{(1+D a)} \eta_{o}
$$

where $D a$ is a deposition Damköhler number. For $D a \gg>1$, the deposition is diffusion limited and the $\eta=\eta_{o} \propto P e_{g}^{-2 / 3}$ behavior is observed (no energy barrier). For $D a<<1$, the capture efficiency decreases as $\eta \propto P e_{g}^{-1}$ and the deposition becomes reaction limited: RLD regime (high energy barrier). Equation 4 shows the coupling between the two stages of the deposition process: the transfer of particles from bulk to the interfacial zone by convection-diffusion, and the deposition according to a surface first order reaction.

Thus, if the colloidal approach is applicable to asphaltenes, their deposition kinetics should obey such types of scaling laws. Moreover, and contrary to stable particles, asphaltene deposition is known to be a continuous process [23]. Hence, a multilayer deposition is expected leading to a progressive and continuous reduction of the pore throat size and shear rate increase in pore constrictions. It could be anticipated that, at a minimum threshold value of shear rate, the deposition rate will be slowed down either by entrainment or detachment. If the shear rate becomes high enough, a non-retention regime could be achieved at a given critical shear rate value with a stable and uniform permeability reduction. This could happen when hydrodynamic forces counterbalance exactly the maximum adhesion forces. If this critical shear rate could not be achieved in the system, a progressive bridging will occur, provoking the progressive plugging of the porous medium [12, 13, 24].

\section{BRIEF ON THE PREVIOUS VALIDATION WORK}

The main initial hypotheses underlying the use of this approach for asphaltene deposition were the following:

- Asphaltenic crude oils can be considered as colloidal systems. This means that asphaltenes exist in crude oils as colloidal particles submitted to their Brownian diffusion. They may undergo aggregation whose kinetics is controlled by the inter-particle interaction forces. Finestein $e t$ al. [25, 26] and Burya et al. [27] bring considerable experimental evidences supporting this view. Both groups of authors shown that asphaltene aggregation kinetics can be described according to the well known Diffusion Limited Aggregation (DLA) or Reaction Limited Aggregation (RLA) processes. Using an original optical scheme allow- ing the investigation of asphaltene aggregation behavior in opaque crude oil, Burya et al. evidenced the occurrence, near the flocculation threshold, of a crossover between the two aggregation regimes when the asphaltene concentration is slightly higher than the CMC.

- Asphaltene dispersions behave as colloidal systems also under dynamic conditions in a porous matrix. Therefore, their deposition kinetics should obey the same general scaling laws as colloids with their specific feature appearing only in the pre-factors of the scaling laws.

- Asphaltene deposition proceeds as multilayer formation on the pore surface (surface aggregation) that could be limited by shear rate (erosion effect).

Extensive experimental work, under both well controlled model conditions and actual ones, has been devoted to the validation of the proposed deposition kinetic laws derived from the "Colloidal Approach". Rajoub [28] studied first the monolayer deposition kinetics using very dilute solutions of Safania asphaltenes in toluene. Using coreflood tests, a mean hydrodynamic thickness of the deposit has been estimated for such a monolayer and found to be of about $\delta_{h}=5.8 \mathrm{~nm}$. This result is in agreement with the mean asphaltene particle size in toluene determined by SAXS [25] and SANS [29]. Then, Rajoub showed that the monolayer deposition takes place according to the Diffusion Limited Deposition (DLD) regime. Finally, he carried out experiments in porous media in order to evidence the multilayer deposition, using Safania asphaltenes dissolved in toluene and Fontainebleau sandstone cores. He concluded that, once the monolayer is formed, the porous media damage induced by asphaltene deposition continues increasing in successive steps corresponding to multilayer deposition (adsorption isotherm in steps). The shear rate limitation of multilayer deposition has been experimentally evidenced by Nabzar et al. [12, 13] and Rajoub [28]. Moreover, it was clearly demonstrated that this shear rate limitation results from a dynamic equilibrium between hydrodynamic and adhesion forces. Recently [15, 18], a systematic and thorough experimental investigation of the asphaltene deposition kinetics has been performed using different systems and under different experimental conditions. These include, first, a model system that consisted in Safania asphaltene dissolved in toluene and capillaries and more representative systems that consisted in three different crude oils (Weyburn, Hassi Messaoud and Arabian light) and Fontainebleau sandstones. Regarding model system and Weyburn crude oil, it was concluded that [15]:

- Asphaltene deposition kinetics, indeed obeys the scaling law of the colloidal approach.

- In the asphaltene deposition process, two main deposition regimes have been distinguished:

- At low shear rate, and up to a first critical value (lower critical shear rate: $\gamma_{\mathrm{cl}}$ ), the deposition is mainly 
diffusion-controlled and obeys the classical $s=2 / 3$ power law (Equation 3 above) of the Diffusion Limited Deposition regime.

- Beyond $\gamma_{c l}$, and up to a second critical value (upper critical shear rate: $\gamma_{\mathrm{cu}}$ ), a new deposition regime has been evidenced. This regime is characterized by a deposition kinetic law with a new universal (independent of system characteristics: asphaltene and porous medium) exponent $s=5 / 3$. This new regime is called SLD that stands for Shear Limited Deposition as it was inferred that it results from the superposition of the previous DLD regime and a shear contribution that slows down the deposition kinetics proportionally to shear rate. That is: $s=5 / 3=2 / 3+1$.

Beyond $\gamma_{\mathrm{cu}}$, a residual deposition, whose extent and kinetics are independent of flow rate, was observed in some experiments. $\gamma_{\mathrm{cu}}$ has not been reached in all the experiments, but can be estimated from the extrapolation of the previous SLD regime to zero or to the residual deposition value. This $\gamma_{\mathrm{cu}}$ has been identified as the critical shear rate for complete asphaltene multilayer deposition limitation.

- Finally, it was shown that both critical shear rates $\gamma_{\mathrm{cl}}$ and $\gamma_{c u}$ depend on asphaltene stability state. They increase with increasing instability: increasing $n$-heptane fraction in the solvent and/or decreasing resin content. Both effects increase the asphatene/asphaltene interactions, and thus, the shear rate required to overcome the adhesion forces.

\section{ADDITIONAL EXPERIMENTAL SUPPORT}

\subsection{Experimental Methods and Systems}

During our experimental validation work, asphaltene deposition kinetics has been investigated as a function of the main controlling parameters such as flow rate, asphaltene aggregation state, resin content and crude oil origin. The study has been performed, first under well controlled conditions using model fluids (ideal systems), and then under more representative conditions using crude oils (actual systems) and capillaries and/or outcrop sandstones.

\subsubsection{Materials}

For the experiments with the ideal system, asphaltenes were first extracted from Safanya crude oil using either n-pentane or $n$-heptane precipitation method, and then dissolved in toluene. For the experiments with actual systems, Weyburn, Hassi Messaoud and Arabian Light crude oils were used. All of these crude oils were filtered at $0.45 \mu \mathrm{m}$ to remove any residual asphaltene aggregates. The density, viscosity and SARA analysis are presented in Table 1.
TABLE 1

Properties and SARA analysis of the crude oils used in actual system experiments

\begin{tabular}{|c|c|c|c|c|c|c|}
\hline \multirow{2}{*}{ Crude oil } & \multirow{2}{*}{$\begin{array}{c}\rho \\
\left(\mathrm{g} / \mathrm{cm}^{3}\right)\end{array}$} & \multirow{2}{*}{$\begin{array}{c}\mu \\
(\mathrm{cP})\end{array}$} & \multicolumn{4}{|c|}{ SARA Analysis (\%) } \\
\hline & & & Saturates & Aromatics & Resins & Asphaltenes \\
\hline Weyburn & 0.8680 & 0.9134 & 40.10 & 46.10 & 8.50 & 5.30 \\
\hline Arabian Light & 0.8545 & 2.5300 & 42.00 & 30.00 & 25.00 & 3.00 \\
\hline $\begin{array}{l}\text { Hassi } \\
\text { Messaoud }\end{array}$ & 0.8429 & 0.9764 & 70.50 & 25.50 & 3.30 & 0.15 \\
\hline
\end{tabular}

The flocculation onsets were determined using the HotierRobin technique [18]. They were found to be $68.0 \%$ of $n$-heptane for the ideal system and $55.2 \%$ of $n$-heptane for Weyburn crude oil, 52.5\% of $n$-heptane for Arabian Light crude oil and $60.0 \%$ of $n$-heptane for Hassi Messaoud crude oil.

The porous media used were Fontainebleau sandstone cores. The values of core porosity are between 7 and $15 \%$. The permeability was determined before each test using pure toluene as solvent. The values of the initial permeability were between 25 and $780 \mathrm{mD}$. The cores dimensions used were $2.3 \mathrm{~cm}$ in diameter and $5 \mathrm{~cm}$ in length.

\subsubsection{Experimental Set-Up}

Both capillary flow and coreflood tests have been used during the study. For capillary flow, we used stainless steel capillaries of different inner diameters. For coreflood experiments, we used Fontainebleau cores. The experimental set-up consisted in a Hassler core holder cell, two positive displacement pumps, two mixers, a crude oil cell, two pressure transducers and a data acquisition system (DAS). The full set-up is shown in Figure 3. During all the experiments, the pressure drop across the medium (capillary or core) was monitored. In the experiments with the ideal systems, the inlet and outlet asphaltene concentrations were registered using an UV-VIS spectrophotometer at $600 \mathrm{~nm}$ wavelength.

\subsubsection{Experimental Methodology}

The experimental work consisted in obtaining the capture efficiency as a function of the shear rate under different experimental conditions. These include asphaltene aggregation state that was controlled through $n$-heptane addition, resin content and oil nature. The capture efficiency is experimentally reached using either outlet concentration (porous media with model systems) or transient pressure (capillary flow and porous media with actual systems) measurements. In the first case, the capture efficiency is given by $[30,31]$ :

$$
\eta=\beta \eta_{0}=\frac{4 d_{g}}{6\left(1-\phi_{i}\right) L_{\text {core }}} \operatorname{Ln}\left(\frac{C_{o}}{C_{\text {plateau }}}\right)_{\text {coverage } \rightarrow 0}
$$




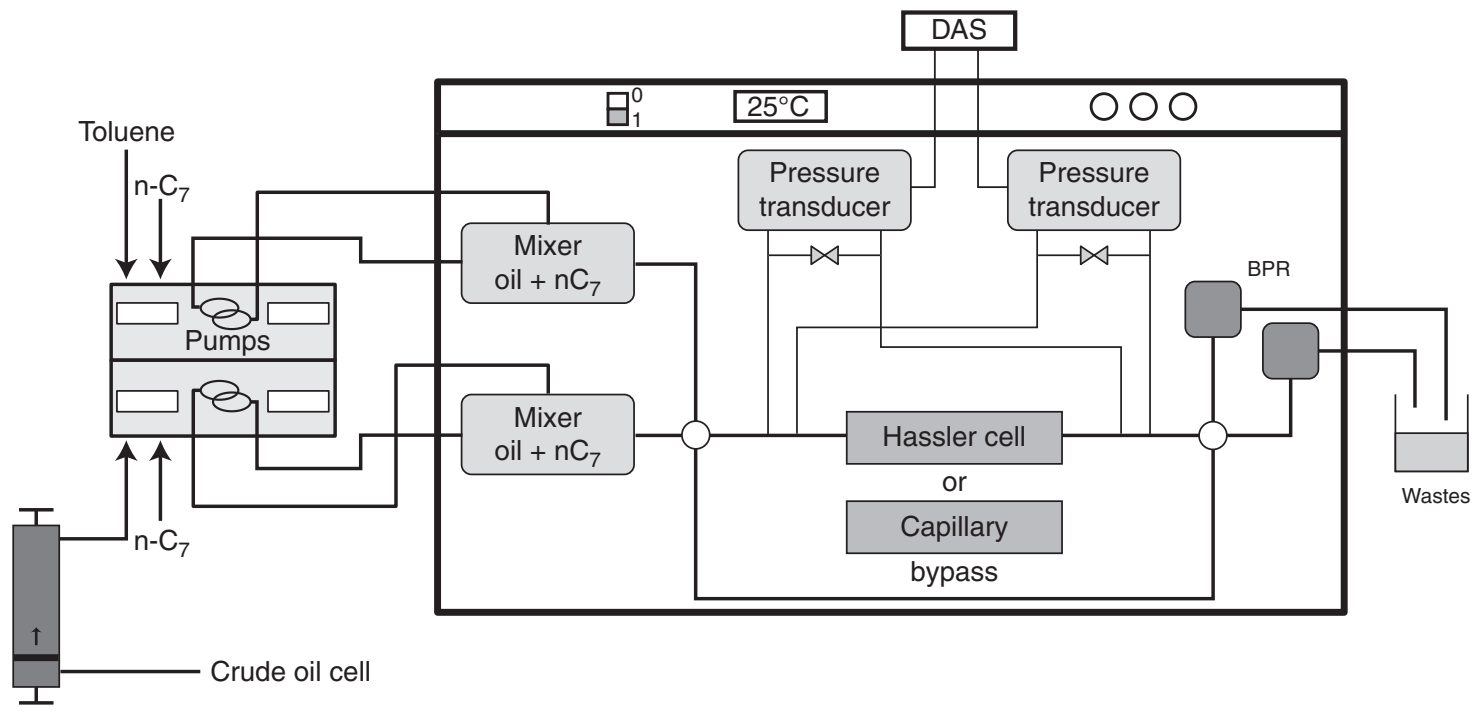

Figure 3

Experimental Set-Up.

where $\phi_{\mathrm{t}}$ is the porosity, $L_{\text {core }}$ is the core length, $C_{o}$ is the injected asphaltene concentration, $C_{\text {plateau }}$ is the asphaltene concentration once the plateau is achieved, $\eta_{0}$ the capture efficiency without energy barrier $(\beta=1)$.

In the second case, where asphaltene concentration can not be measured, it can be demonstrated that the capture efficiency is proportional to the mobility reduction rate with respect to the number of pores volumes injected (see Appendix):

$$
\eta \propto \frac{d R_{m}}{d(P V I)}
$$

with the mobility reduction, $R_{m}$, defined as:

$$
R_{m}(t)=\frac{\Delta P(t)}{\Delta P_{0}}
$$

Regarding the shear rate in porous media, it was calculated as follows:

$$
\gamma=\frac{4 \cdot c \cdot u}{r_{p}^{o}}
$$

where $c$ is an empirical constant $(c=2.5$ for Fontainebleau sandstones), $r_{p}^{o}$ is the initial mean hydrodynamic pore throat radius and $u$ is the interstitial velocity.

In the general case of multiphase flow, the interstitial velocity of phase $j$ can be calculated applying Dupuit's equation $[11,32]$ :

$$
u_{j}=\frac{v_{j}}{\phi\left(S_{j}-S_{j i r}\right)} \tau
$$

where $\tau$ is the tortuosity, $\phi$ the porosity of the porous medium, $S_{j}$ the saturation, $S_{j \text { irr }}$ the irreducible saturation and $v_{j}$ the superficial velocity of phase $j$.

In the case of single phase flow, Equation 9 reduces to:

$$
u=\frac{Q}{\Sigma \phi} \tau
$$

where $Q$ is the flow rate and $\Sigma$ the cross section of the porous medium. In the present work, we considered a single phase flow as our porous media were fully saturated with hydrocarbon phase (no water was present) where asphaltene are suspended as colloidal particles. According to Civan [11], the interstitial velocity in coarse porous media can be calculated using Equation 10 as: $u=Q /\left(\phi_{t} \Sigma\right)\left(\tau \sim 1\right.$ and $\left.\phi=\phi_{i}\right)$. Actually, in our case, the tortuosity of the porous medium can be considered as encompassed in the empirical constant $c$.

\subsection{Results and Discussion}

\subsubsection{Model System}

\section{Shear Limited Deposition}

We started the study performing capillary flow experiments using ideal systems that consisted in Safania asphaltene powder dissolved in toluene and $n$-heptane as flocculent. 
The asphaltene concentration was of about $1000 \mathrm{ppm}$.

The impact of the shear rate on asphaltene deposition kinetics has been investigated according to the two following procedures:

- Using the same capillary and injecting at different flow rates in separate experiments (Fig. 4).

- Using the same capillary and performing stepwise flow rate changes during the same experiment (Fig. 6).

Figures $4 a-c$ show clearly that when the shear rate is increased through increasing the injection flow rate, the deposition kinetic is increasingly slowed down. Comparison of these figures shows that the same conclusion can be drawn if the shear rate is increased through decreasing the capillary inner diameter. This is highlighted in Figure 5 that reports comparison of the results obtained using the same flow rate and capillaries of different inner diameters.

The shapes of all the experimental curves in Figures 4 and 5 show that a more or less induction period is always required for the multilayer deposition to be effective in flow restriction. This induction time is attributed to the formation of the first layer at least on a significant part of the capillary inner surface.

It can be seen also in Figures $4 \mathrm{~b}$ and $\mathrm{c}$ that, beyond some critical shear rate value $\left(\gamma_{\mathrm{cu}}\right)$, the deposition (both extent and
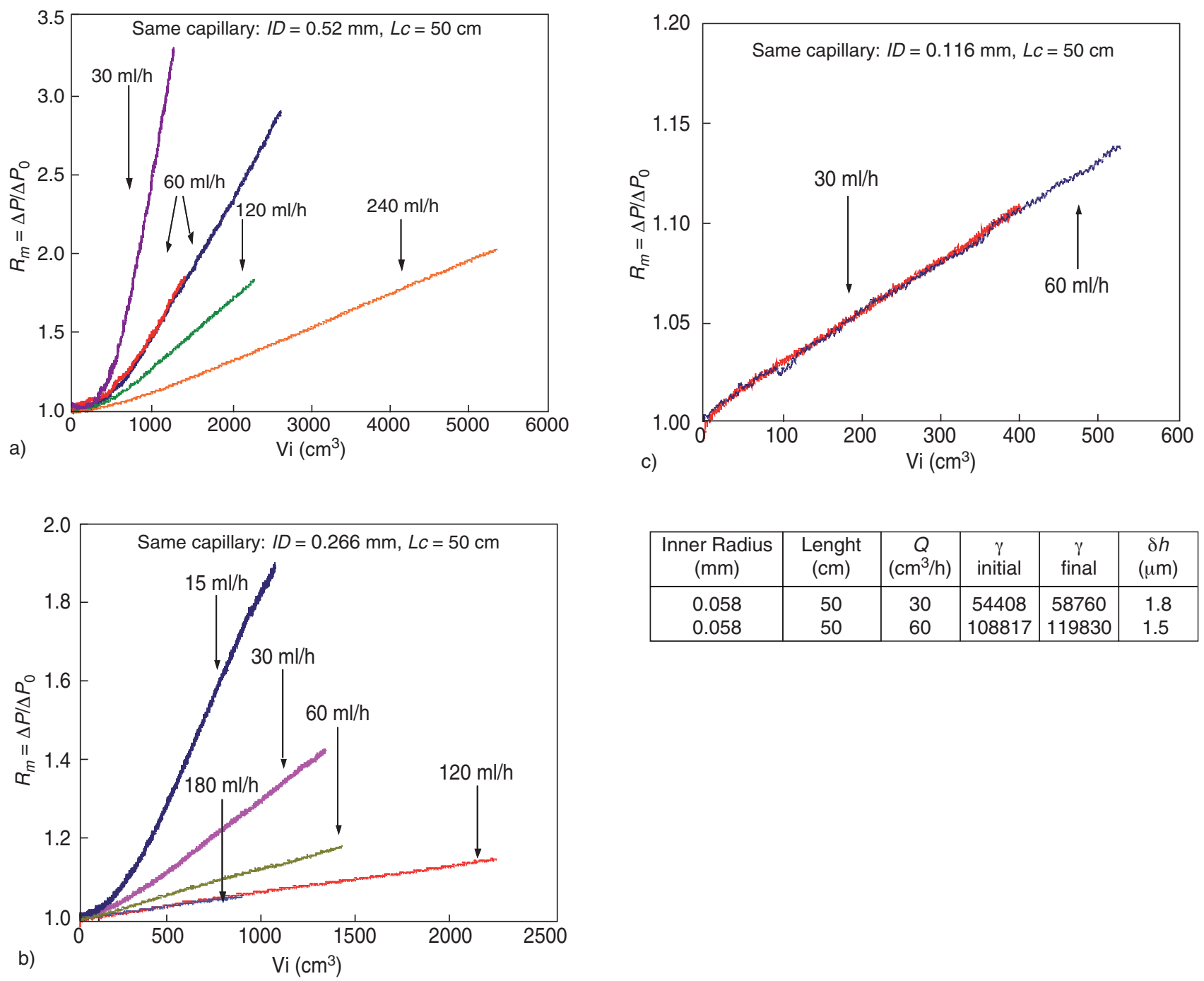

\begin{tabular}{|c|c|c|c|c|c|}
\hline $\begin{array}{c}\text { Inner Radius } \\
(\mathrm{mm})\end{array}$ & $\begin{array}{c}\text { Lenght } \\
(\mathrm{cm})\end{array}$ & $\begin{array}{c}Q \\
\left(\mathrm{~cm}^{3} / \mathrm{h}\right)\end{array}$ & $\begin{array}{c}\gamma \\
\text { initial }\end{array}$ & $\begin{array}{c}\gamma \\
\text { final }\end{array}$ & $\begin{array}{c}\delta h \\
(\mu \mathrm{m})\end{array}$ \\
\hline 0.058 & 50 & 30 & 54408 & 58760 & 1.8 \\
0.058 & 50 & 60 & 108817 & 119830 & 1.5 \\
\hline
\end{tabular}

Figure 4

Experimental evidence of shear limitation at $20 \%$ Toluene and $80 \% \mathrm{n}-\mathrm{C} 7$. Separate experiments with the same capillary $(I D=0.52 \mathrm{~mm}(\mathrm{a})$; $0.226 \mathrm{~mm}(\mathrm{~b}) ; 0.116 \mathrm{~mm}$ (c) and $L c=50 \mathrm{~cm}$ ) and different flow rates. 
kinetics) becomes independent of flow rate. At the end of the experiment, this residual deposition corresponds to an estimated mean hydrodynamic deposit thickness of about $1 \mu \mathrm{m}$ (see table in Fig. 4c). It could be attributed to a progressive saturation of the first monolayer in direct contact with inner surface of the capillary. Thus, beyond $\gamma_{c u}$ only the induction period is observed, while the multilayer formation is totally hindered.

More interesting are the results presented in Figure 6 corresponding to stepwise flow rate changes during the same test. This figure clearly shows experimental evidence that asphaltene deposition could be totally hindered by the shear
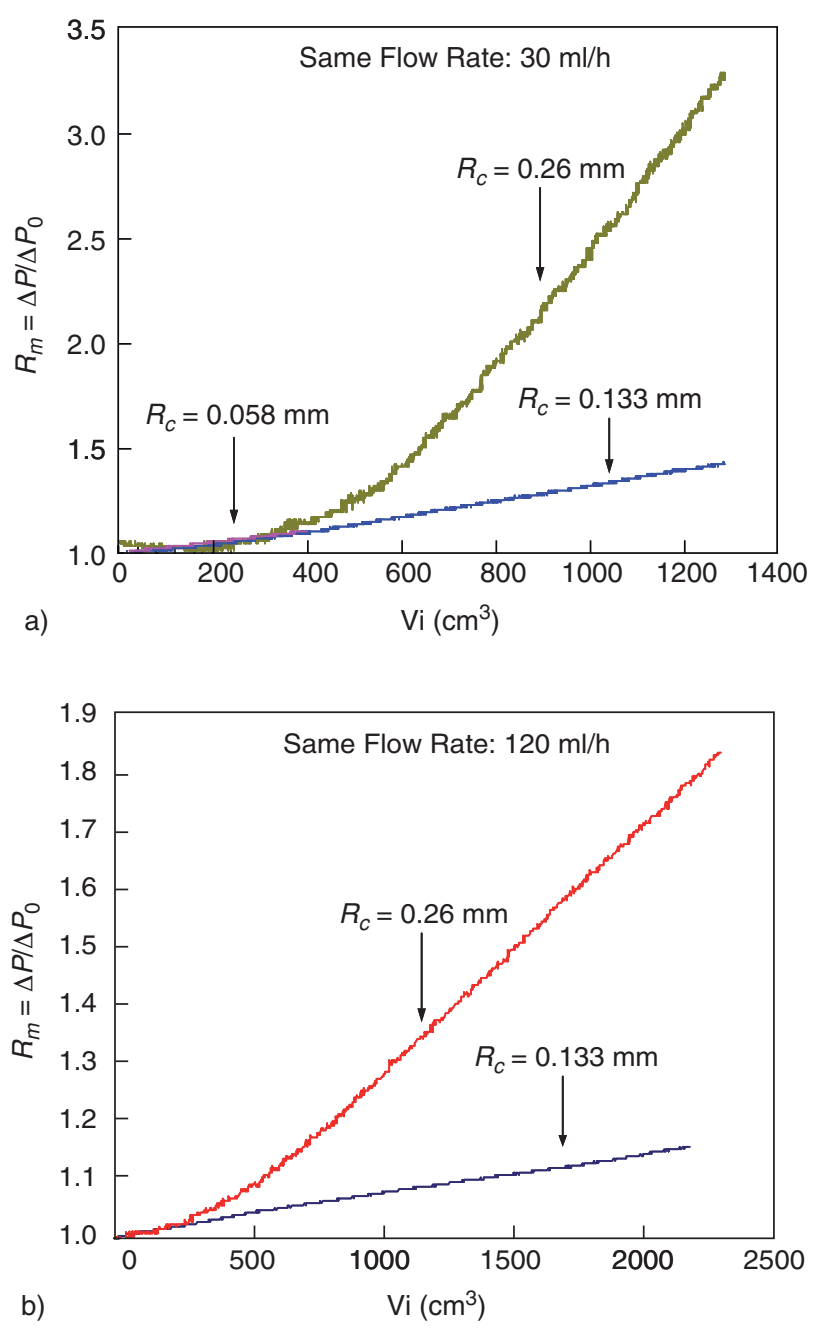

Figure 5

Experimental evidence of shear limitation at $20 \%$ Toluene and $80 \%$ n-C7. Separate experiments with different capillaries@ $30 \mathrm{ml} / \mathrm{h}(\mathrm{a}) ; 120 \mathrm{ml} / \mathrm{h}$ (b). rate. Indeed, it can be seen on this figure that the deposition kinetics is again slowed down upon increasing the flow rate. When a critical shear rate has been reached, the asphaltene deposition stops and resumes again when the flow rate is slightly decreased below the critical value. These results put clearly into evidence the existence of a critical shear rate that totally hinders the asphaltene multilayer deposition. In addition, this demonstrates that such limitation results from a dynamic equilibrium between hydrodynamic and adhesion forces that can be mathematically expressed as:

$$
F_{H}=\pi \mu \gamma_{c} a_{p}^{2}=F_{A}=\frac{H \cdot a_{p}}{12 \delta^{2}}
$$

where $\mu$ is the viscosity, $\gamma_{c}$ the critical shear rate, $a_{p}$ the particle radius, $H$ the Hamaker constant and $\delta$ the distance of minimum approach between the particle and the collector.

\section{Deposition Kinetics}

The deposition kinetics has been investigated by extracting the capture efficiencies from the previous experimental results. The results are shown in Figure 7 as the capture efficiency $v s$. the initial shear rate.

The results show that the deposition kinetics obeys the general scaling law of the form:

$$
\eta \propto A \cdot \gamma^{-5 / 3}
$$

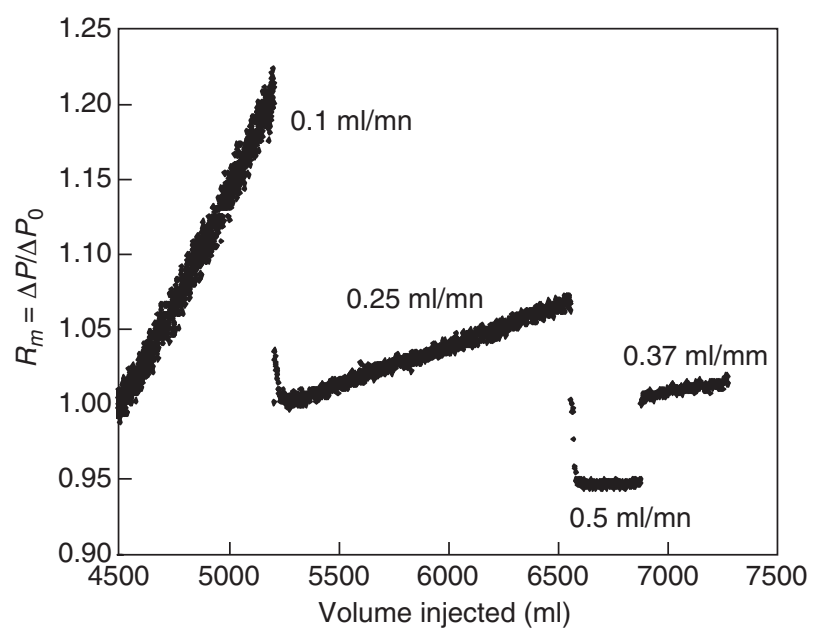

Figure 6

Experimental evidence of shear limitation at $20 \%$ Toluene and $80 \% \mathrm{n}-\mathrm{C} 7$. Experiment with the same capillary and stepwise flow rate change. 


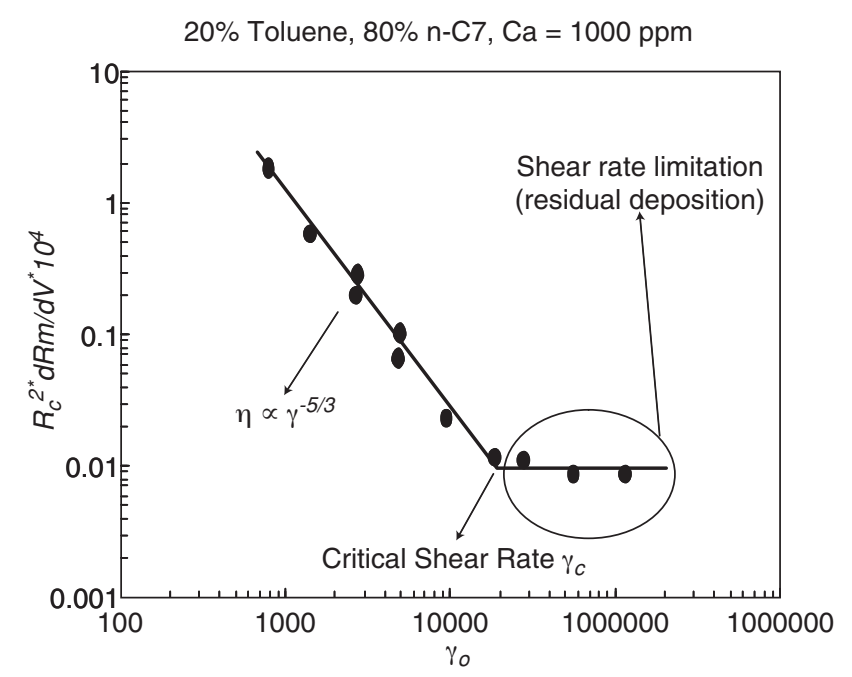

Figure 7

Deposition kinetics with model system.

with this model system, and under the experimental conditions used, only the Shear Limited Deposition regime (SLD) is obtained. As mentioned above, this regime actually results from the classical Diffusion Limited Deposition according to the shear rate $-2 / 3$ power low and an additional shear limitation contribution that varies as the shear rate to the power -1 .

The result of Figure 7 also clearly evidences the upper critical shear rate corresponding to the asphaltene multilayer deposition limitation as well as the residual deposition.

\subsubsection{Actual Systems}

\section{Weyburn Crude Oil}

In our previous work with actual systems, we used Weyburn crude oil and Fontainebleau sandstone and we investigated the impact of asphaltene aggregation state as controlled by $\mathrm{n}-\mathrm{C} 7$ percentage in the solvent. This work confirmed the validity of the colloidal approach with this actual system. Moreover, the existence of a shear limitation onset (lower critical shear rate) below which the classical $-2 / 3$ DLD regime is recovered (no shear limitation) and beyond which the shear rate starts hindering the multilayer deposition has been experimentally put into evidence. Figure 8 summarizes these previous results with Weyburn crude oil.

Three series of experiments similar to those reported in Figure 8 have been performed using new actual crude oils: Hassi Messaoud (HM) crude oil and Arabian light (AL) crude oil.

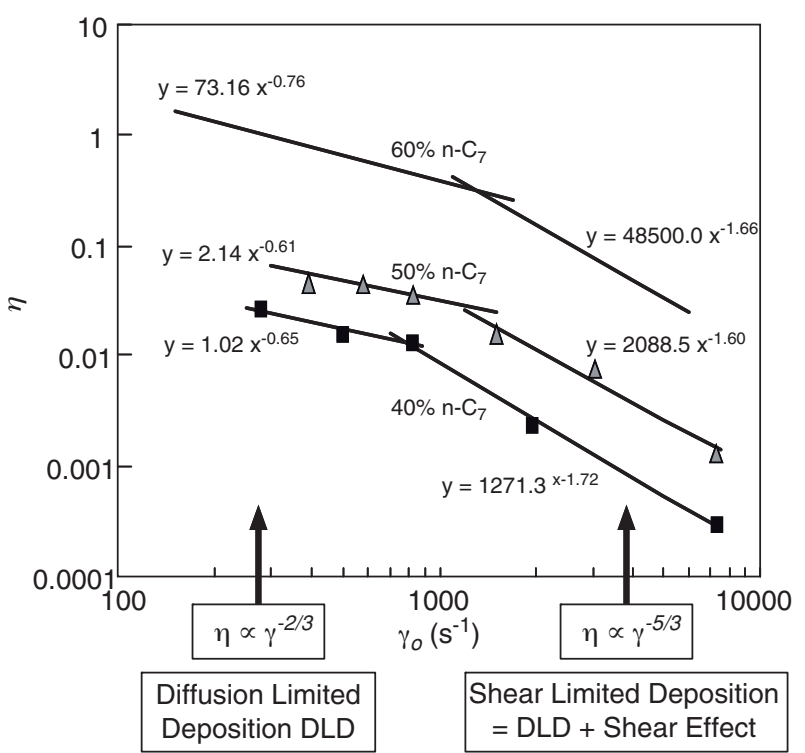

Figure 8

Asphaltene deposition kinetics from Weyburn actual crude oil.

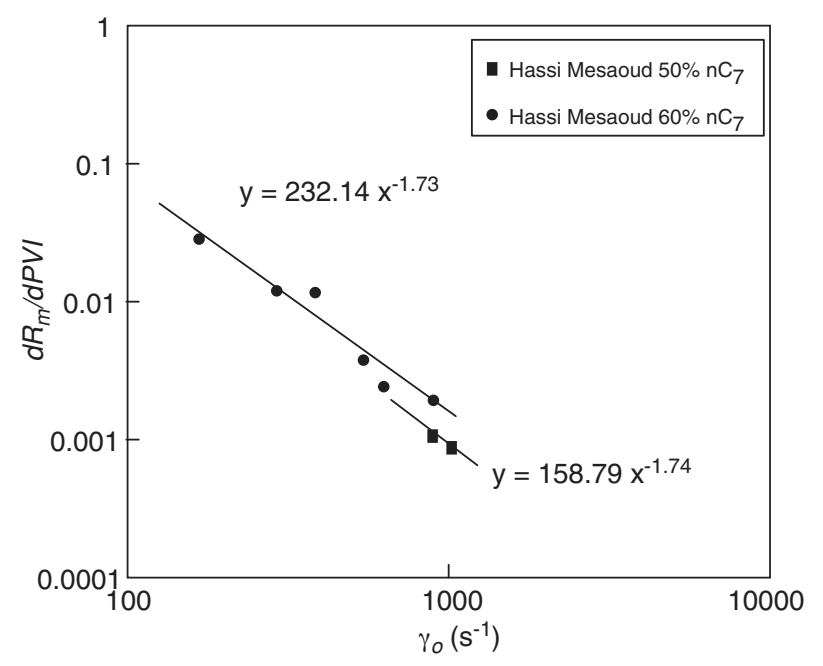

Figure 9

Asphaltene deposition kinetics from Hassi Messaoud actual crude oil.

\section{Hassi Messaoud Crude Oil}

With HM crude oil, we investigated the impact of asphaltene aggregation state at two $n$-heptane percentages: below (50\%) and close to (60\%) the flocculation threshold 


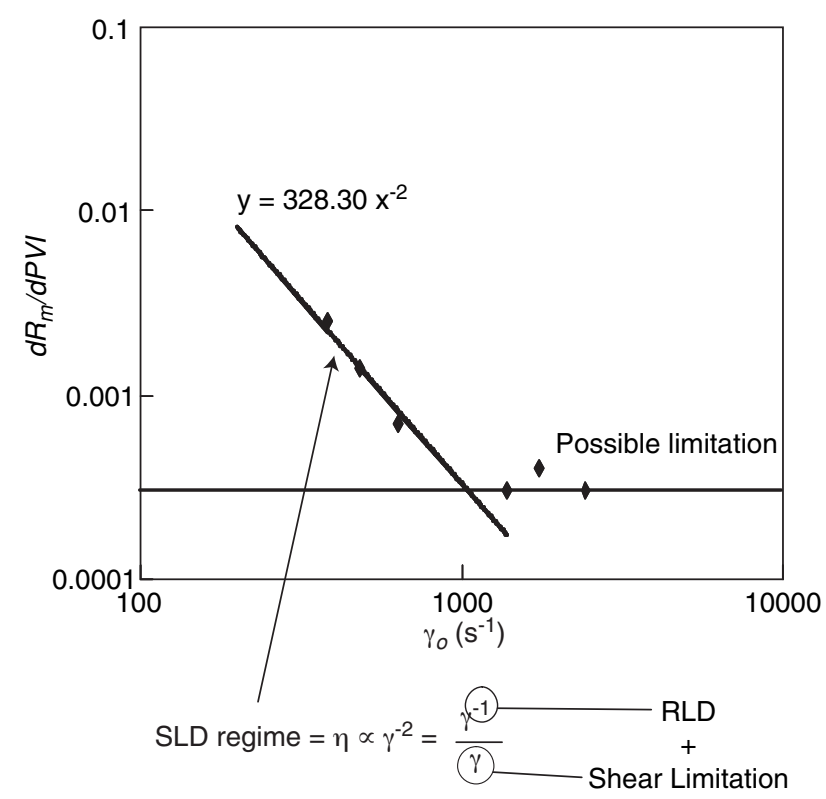

Figure 10

Asphaltene deposition kinetics from Arabian light actual crude oil.

(68\%). The results of the deposition kinetics are presented in Figure 9. It can be observed in this figure that the deposition kinetic obeys again the general scaling law obtained with model system and with actual Weyburn crude oil in the SLD regime. The power law exponent is about $-5 / 3$ independently of $\mathrm{n}-\mathrm{C} 7$ percentage. The collection efficiencies are much lower than with Weyburn crude. It should be noticed here that HM crude oil has much lower asphaltene content that the two others crude oils (see Table 1). Neither a DLD regime nor a residual deposition have been observed with this crude in the range of the shear rates investigated.

\section{Arabian Light Crude Oil}

With this crude oil, the study of the deposition kinetics has been performed without adding $n$-heptane. The result is shown in Figure 10. Two regimes are put into evidence with this crude: the residual deposition regime beyond the upper critical shear rate $\left(\gamma_{\mathrm{cu}}\right)$ that has been clearly observed around $1000 \mathrm{~s}^{-1}$ and the SLD regime. The residual deposition flux $\left(=\eta_{\text {residual }} \cdot Q C_{\mathrm{o}}\right)$ was very low and the deposition was almost negligible. As with HM crude oil, no DLD regime has been observed with this crude in the range of the shear rates investigated.

Regarding SLD regime, it exhibits an interesting feature that was observed for the first time in our investigation.
Indeed, with this crude, the SLD regime exhibits a power law exponent of 2 that, according to our interpretation, reveals that asphaltene deposition from this crude takes place according to the classical RLD regime (exponent $=$ -1 ) instead of DLD regime (exponent $=-2 / 3$ ) as observed with both Weyburn and Hassi Messaoud crude oils. Thus, the shear contribution, varying as the reciprocal of shear rate, leads to the power law exponent of -2 . This reveals the presence of a significant energy barrier facing asphaltene deposition from this crude that is consistent with the very low collection efficiency values and with the absence of $n$-heptane addition as well. In these conditions, asphaltene particle tendency to associate in larger aggregates (flocculation) is very low. As mentioned above, the origin of this stability, and thus, of the energy barrier opposing flocculation is still not very clear.

This interesting result comes in support of the colloidal approach and completes its experimental validation. For this crude, a deposition according to the classical RLD regime with a -1 power law dependence on the shear rate could be anticipated at low shear rate.

Figure 11 provides a graphical comparison of the deposition kinetics in the SLD regime for Hassi Messaoud crude (50\% and 60\% n-C7), Arabian Light crude (0\% n-C7) and Safania asphaltene (40\% Toluene and 60\% n-C7) and Figure 12 provides a graphical synthesis of all the results obtained with actual crude oils.

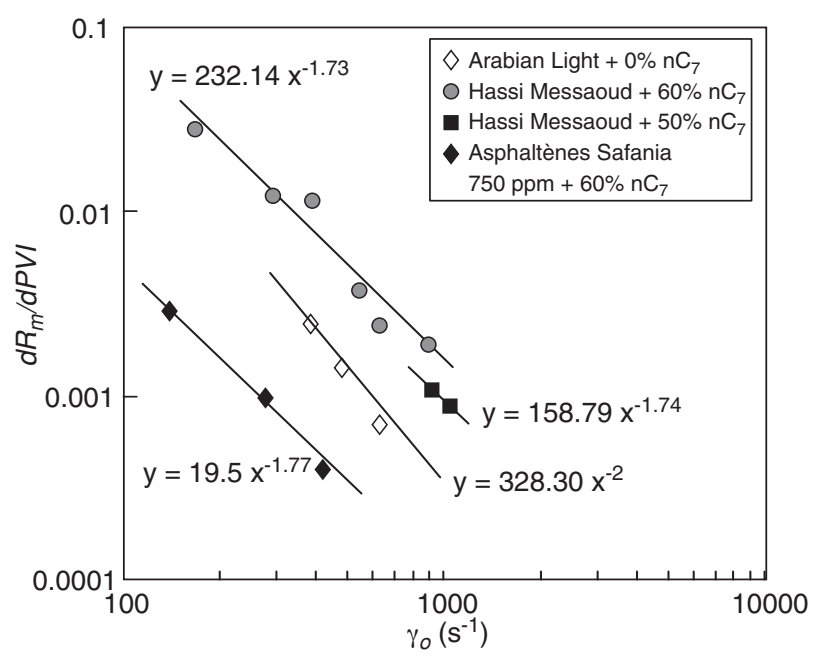

Figure 11

Comparison of the new deposition kinetics and model system results in the SLD regime. 


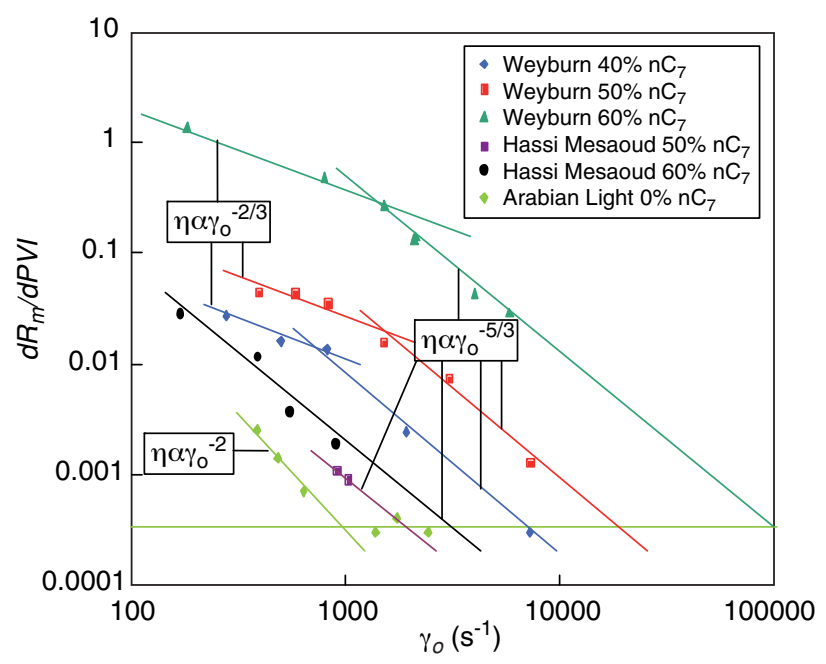

Figure 12

Asphaltene deposition kinetics from three actual crude oils.

\section{CONCLUSIONS}

The results obtained in this experimental study allowed us to complete the experimental validation of the colloidal approach we used for asphaltene deposition modelling. Asphaltene deposition in porous media has been thoroughly investigated as a function of relevant parameters such flow rate, asphaltene aggregation state (as controlled by $\mathrm{n}-\mathrm{C} 7$ addition or resin content) and asphaltene origin and environment (model system, three different actual crude oils). It was experimentally confirmed that:

- Asphaltene deposition in porous media is a continuous process resulting from multilayer formation that could be limited by the shear rate

- Asphaltene deposition kinetics obeys the general scaling law of colloid deposition in porous media.

- The capture efficiency varies as:

$$
\eta \propto A \cdot \gamma^{-s}
$$

Two deposition regimes have been clearly evidenced:

- At low flow rate and up to a first (lower) critical shear rate (shear contribution Onset: $\gamma_{\mathrm{cl}}$ ), the deposition takes place according the classical DLD $(s=2 / 3)$ or $\operatorname{RLD}(s=-1)$ regime.

- Beyond $\gamma_{\mathrm{cl}}$ and up to a second (upper) critical shear rate (multilayer deposition limitation) the deposition rate becomes more sensitive to shear rate than during the previous regime. This new regime is characterised by a power law exponents $s=5 / 3$ (model system, Weyburn, Hassi Messaoud) or $s=2$ (Arabian light). It was inferred that actually, these new exponents encompass the classical ones of $2 / 3$ or 1 and an effect of shear limitation that, accordingly, is supposed to vary as the shear rate to the power -1 .

- The exponents of the deposition kinetic power law are universal exponents independent of system (fluid and porous medium) nature and geometry. All system characteristics are encompassed in the pre-factor $A$ that, for a given porous media, depends on asphaltene nature and aggregation state.

- Both the two critical shear rates depend on asphaltene nature and stability state.

- Complete shear limitation of multilayer deposition is thought to result from a dynamic equilibrium between hydrodynamic and maximum asphaltene/asphaltene adhesion forces. This allows us to write down a second important equation as:

$$
F_{H}=\pi \mu \gamma_{c} a_{p}^{2}=F_{A}=\frac{H \cdot a_{p}}{12 \delta^{2}}
$$

Thus, it can be concluded that, indeed, the "colloidal approach" is a promising route for asphaltene deposition modelling. It provides simple and powerful scaling law for the deposition kinetics and a new way (Equations I and II) to couple thermodynamic, hydrodynamic and aggregation kinetic contributions as schematised in Figure 13 and buildup a robust modelling taking into account the actual physics of the asphaltene-induced damage. Experimental validation of this approach under reservoir conditions is now underway.

\section{REFERENCES}

1 Wojtanowicz A.K. et al. (1987) Study on the Effect of Pore Blocking Mechanism Formation Damage, SPE 16233, SPE production Operation Symposium, Oklahomla City, Oklahoma, March 8-10, 1987

2 Nghiem L.X. et al. (1993) Efficient Modeling of Asphaltene Precipitation, SPE 20530, SPE 68th Annual Technical Conference and Exhibition, Houtoun, Texas, October 3-6, 1993

3 Civan F. (1995) Modeling and Simulation of Formation Damage by Organic deposition, First International Symposium in Colloid in Oil Production: Asphaltene and Wax Deposition, ISCOP'95, Rio de Janeiro, November 26-29, 1995

4 Gruesbeck C., Collins R.E. (1982) Entrainment and deposition of fine particles in Porous media, SPEJ 22, 6, 847-856.

5 Ali M.A., Islam M.R. (1998) The Effect of Asphaltene Precipitation on Carbonate-Rock Permeability: An Experimental and Numerical Approach, SPE Prod. Facil., 178-183.

6 Wang S., Civan F., Strycker A.R. (1999) Simulation of Paraffin and Asphaltene Deposition in Porous Media, SPE 50746, SPE International Symposium on Oilfield Chemistry, Houston, February 16-19, 1999. 


\section{Hydrodynamic Force}

Maximum Adhesion Force
Deposition Kinetics

@ dynamic equilibrium

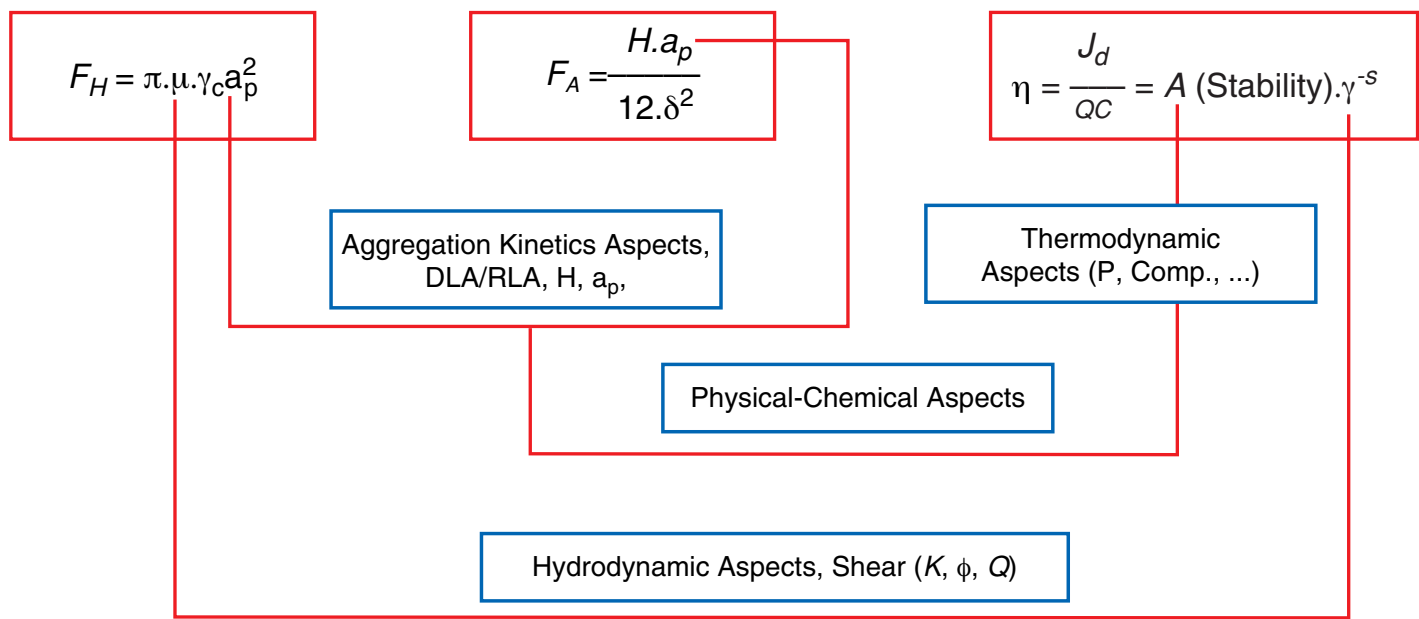

Figure 13

Physical-chemical and hydrodynamic aspects in asphaltene deposition.

7 Wang S., Civan F. (2001) Productivity Decline of Vertical and Horizontal Wells by Asphaltene Deposition in Petroleum Reservoirs, SPE 64991, SPE International Symposium on Oilfield Chemistry, Houston, February 13-16, 2001.

8 Leontaritis K. (1998) Asphaltene Near-Wellbore Formation Damage Modeling, SPE 39446, SPE Formation Damga Control Conference, Lafayette, Louisiana, February 18-19, 1998.

9 Wang S., Civan F. (2005) Modelling Formation Damage by Asphaltene Deposition During Primary Oil Recovery, J. Energ. Resour. Technol. 127, 4, 310-317.

10 Wang S., Civan F. (2005) Model Assisted Analysis of Simultaneous Paraffin and Asphaltene Deposition in laboratory core Tests, J. Energ. Resour. Technol. 127, 4, 318-322.

11 Civan F. (2007) Chapter 14: Formation Damage by Organic Deposition, in Reservoir Formation Damage-Fundamentals, Modeling, Assessment, and Mitigation, 2nd ed., Gulf Professional Pub., Elsevier.

12 Nabzar L., Romanova U.G., Yusupova T.N., Longeron D. (2001) Asphaltene Deposition in the Porous Media: Modelling and Experimental Studies, Advanced Methods of Enhanced Oil Recovery: Theory and Practice, 8th Specialized International Exhibition "Oil, Gas \& Petrochemistry 2001", Kazan, The Republic of Tatarstan, Russia, 5-8 September 2001.

13 Nabzar L., Romanova U.G., Rajoub Y., Longeron D. (2002) Experimental Study and Modelling of Asphaltene Deposition in Porous Media, International Conference on Heavy Organics Depositions-HOD, Puerto Vallarta, Jalisco, Mexico, 17-21 November 2002.
14 Nabzar L., Romanova U.G., Rajoub Y., Longeron D. (2002) Experimental Study and Modelling of Asphaltene Deposition in Porous Media, International Symposium and Exhibition on Formation Damage Control, Lafayette, Louisiana, USA, 20-21 February 2002.

15 Nabzar L., Aguilera M.E., Rajoub Y. (2005) Experimental Study on Asphaltene-Induced Formation Damage, SPE 93062, SPE International Symposium on Oilfield Chemistry, Houston, Texas, USA, 2-4 February 2005.

16 Chauveteau G. et al. (1998) Physics and Modeling of Permeability Damage Induced by Particle Deposition, SPE 39463, SPE International Symposium on Formation Damage Control, Lafayette, USA, Feb. 18-19, 1998.

17 Rousseau D., Hadi L., Nabzar L. (2007) PWRI-Induced Injectivity Decline. New Insights on In-Depth Particle Deposition Mechanisms, SPE 107666, SPE European Formation Damage Conference, Scheveningen, The Netherlands, 30 May-1 June.

18 Aguiléra M.E. (2006) Modélisation physique et prévention de l'endommagement des abords des puits par les bruts asphalténiques, PhD Thesis, Université Louis Pasteur (ULP), Strasbourg.

19 Levich V.G. (1962) Physicochemical Hydrodynamics, Prentice Hall, Englewood Cliffs, N.J.

20 Happel J., Brenner H. (1965) Low Reynolds Number Hydrodynamics, Printice-Hall International Series in the Physical and Chemical Engineering Sciences, Prentice Hall, Engleword Cliffs, N.J. 
21 Nabzar L. et al. (1997) Water Quality and Well Injectivity, 9th European Symposium on Improved Oil Recovery, The Hague, The Netherlands, 20-22 October, 1997.

22 Spielman L.A., Friedlander S.K. (1974) Role of Electrical Double Layer in Particle Deposition by Convective Diffusion, $J$. Colloid Interf. Sci. 46, 22.

23 Piro G. et al. (1996) Asphaltene Adsorption onto Formation Rock: An Approach to Asphaltene Formation Damage Prevention, SPEFE, p. 156.

24 Minssieux L., Nabzar L., Chauveteau G., Longeron D., Bensalem R. (1998) Permeability damage due to asphaltenes Deposit: Experimental and Modeling Aspects, Oil Gas Sci. Technol. 53, 3, 313-327.

25 Fenistein D., Barre L. (2001) Experimental Measurement of the Mass Distribution of Petroleum Asphaltene Aggregates Using Ultracentrifugation and Small Angle X-Ray Scattering, Fuel 80, 283.

26 Fenistein D., Barre L., Frot D. (2000) Oil Gas Sci. Technol. 55, $1,123-128$.
27 Burya Y.G. (2001) Light Scattering Study of petroleum Asphaltene Aggregation, Appl. Optics 40, 24, 4028.

28 Rajoub Y. (2003) Étude expérimentale et modélisation de l'endommagement aux abords des puits lors de la production de bruts asphalténiques, $P h D$ Thesis, Université Louis Pasteur (ULP), Strasbourg.

29 Sheu E. (1996) Physics of Asphaltene Micelles and Microemulsions - Theory and Experiments, J. Phys.: Condens. Mat. 8, A125.

30 Tien C. (1989) Granular Filtration of Aerosols and Hydrosols, Buttherworth-Heinmann, Woburn, MA., p. 365.

31 Elimelech M. (1991) J. Colloid Interf. Sci. 146, 2, 337-352.

32 Dupuit J. (1963) Études Théoriques et Pratiques sur le Mouvement des Eaux dans les Canaux Découverts et à travers les Terrains perméables, 2nd ed., Dunod, Paris.

Final manuscript received in October 2007 


\section{APPENDIX}

Experimental estimation of the capture efficiency from the mobility reduction rate.

The bare collector capture efficiency is defined as the relationship between the mean particles deposition flux and the incident flux:

$$
\eta=\frac{\text { mean deposition flux }}{\text { incident flux }}=\frac{J}{Q \cdot C_{o}}
$$

$\eta$ is the capture efficiency, $J$ is the mean deposition flux, $Q$ is the flow rate and $C_{o}$ is the injected asphaltene concentration.

The mean deposition flux can be expressed as:

$$
J=\langle j\rangle \cdot \Sigma_{a}^{p}=\rho_{d} \cdot\left(\frac{d \delta_{h}}{d t}\right) \Sigma_{a}^{p}
$$

where $\rho_{d}$ is the deposit density $(\mathrm{g} / \mathrm{l}), \delta_{h}$ is the deposition thickness and $\sum_{a}^{p}$ is the surface accessible to deposition. When a stable deposition regime is reached (the deposition flux is constant and uniform in the whole porous media), the hydrodynamic mean thickness of the deposit may be expressed as:

$$
\delta_{h}=\frac{J}{\rho_{d} \cdot \Sigma_{a}^{p}} \cdot t
$$

On the other hand, using the Poiseuille equation, the mobility reduction is obtained by:

$$
R_{m}=\frac{1}{\left[1-\frac{\delta_{h}}{r_{p}^{o}}\right]^{4}}
$$

where $R_{m}$ is the mobility reduction, $\delta_{h}$ is the mean hydrodynamic thickness of the deposit and $r_{p}^{o}$ is the average initial pore radius.

When $\delta_{h} \ll<r_{p}^{o}$, Equation A-4 becomes:

$$
R_{m}-1 \approx 4 \frac{\delta_{h}}{r_{p}^{o}}
$$

Thus:

$$
R_{m}-1 \approx \frac{4 J}{\rho_{d} \cdot \Sigma_{a}^{p} r_{p}^{0}} t=\frac{4 C_{o}}{\rho_{d} \cdot \Sigma_{a}^{p} \cdot r_{p}^{o}} \eta Q t=\frac{4 C_{o}}{\rho_{d} \cdot \Sigma_{a}^{p} \cdot r_{p}^{o}} \eta V_{p}\left(\frac{V_{i n j}}{V_{p}}\right)
$$

$V_{i n j}$ is the injected volume and $V_{p}$ the pore volume. The number of pore volume injected $(P V I)$ is defined as:

$$
P V I=\frac{Q t}{V_{p}}=\frac{V_{i n j}}{V_{p}}
$$

Therefore, the capture efficiency is proportional to the mobility reduction variation with respect to the number of pore volume injected:

$$
\eta \propto \frac{d R_{m}}{d P V I}
$$

